MIDPI

sciforum
MOL2NET, International Conference Series on Multidisciplinary Sciences

Symposium on Bioactive Natural and Synthetic Products and Their

Therapeutic Potentials

\title{
EVALUATION OF PROTECTIVE EFFECT OF CITRAL ON GASTROESOPHAGEAL REFLUX DISEASE IN EUTROPHIC AND OBESE MICE
}

Ana Carolina Fioretto ${ }^{a}$, Rie Ohara ${ }^{a}$, Maycon Tavares Emílio-Silva ${ }^{a}$, Gabriela Bueno

${ }^{a}$, Vinícius Peixoto Rodrigues ${ }^{a}$, Renata Assunção ${ }^{a}$, Felipe Lima Dario ${ }^{a}$, Victória Gomes ${ }^{a}$, Priscila Romano Raimundo ${ }^{a}$, Lúcia Regina Machado da Rocha ${ }^{a}$, Clélia Akiko Hiruma-Lima ${ }^{a}$.

${ }^{a}$ Departmente of Structural and Functional Biology (Physiology), Institute of Bioscience, São Paulo State University, Botucatu 18618970, São Paulo, Brazil.

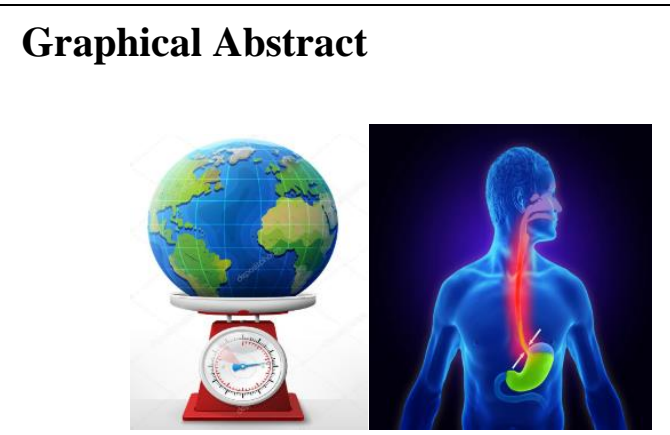

Diseases associated with obesity such as GERD.
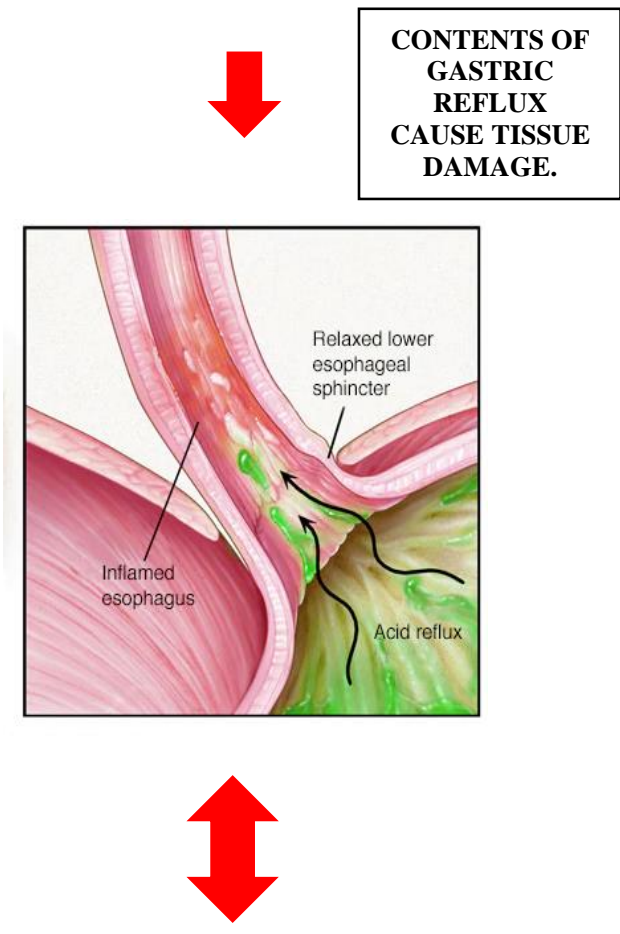

NEW THERAPEUTIC TARGETS SUCH AS PRODUCTS FROM MEDICINAL PLANT SOURCES.

\begin{abstract}
.
The World Health Organization has been warning about the obesity epidemic. Studies have shown the prevalence of diseases associated with obesity, such as gastroesophageal reflux disease (GERD). GERD is a chronic condition resulting from the reflux of stomach contents. Due to tissue damage and local inflammation, defense cells are present in this process, as they indicate an inflammatory process. Currently, the pharmacological therapy used is proton pump inhibitors (PPIs), such as lansoprazole (LZ), but most of the time, PPIs are effective, but their long-term treatment can have a variety of side effects. New therapeutic targets, such as products from medicinal plant sources, end up being much sought after, due to their greater availability and better efficacy. Among them, there is citral (CT), a monoterpene that is present in the composition of essential oils from plants. This monoterpene has several proven pharmacological properties: antiinflammatory, anti-diabetic, anti-adipogenic and gastroprotective action. Therefore, this project aimed to evaluate the effect of CT on GERD in eutrophic and obese animals. Male mice (C57BL/J6) received standard diet (SD) or high-fat diet (HFD) for 18 weeks to induce obesity. The mice were orally treated by gavage (single dose) and, after one hour, underwent the surgical procedure for implantation of gastroesophageal reflux, being euthanized after four hours to collect the esophagus. Body weight gain, adiposity index, food intake, glycemic index, lesion area, measurement of
\end{abstract}




\begin{tabular}{|l|l|}
\hline \hline & $\begin{array}{l}\text { esophageal } \mathrm{pH} \text { and evaluations of the inflammatory process } \\
\text { via determination of MPO activity were analyzed. During the } \\
\text { obesity induction period, the animals in the HFD group } \\
\text { showed a significant increase in body weight and in the } \\
\text { adiposity index, when compared to the SD group. The results } \\
\text { demonstrate that previous treatment with CT in both animals } \\
\text { that received SD and HFD was effective in preventing } \\
\text { gastroesophageal reflux-induced lesions. The results also } \\
\text { showed that in the SD group, there was a decrease in the } \\
\text { pharmacological properties: anti-inflammatory, } \\
\text { anti-diabetic, anti-adipogenic and gastroprotective } \\
\text { action. }\end{array}$ \\
$\begin{array}{l}\text { esophageal pH of the animals that received CT. Regarding the } \\
\text { a significant decrease difference. The MPO enzyme activity } \\
\text { was quantified and there was a significant reduction in the } \\
\text { group treated with CT in the SD group. In the HFD group, this } \\
\text { reduction in MPO activity was evident in the LZ and CT. } \\
\text { Thus, it was observed that CT had a protective effect on } \\
\text { GERD in groups treated with a higher dose of CT in eutrophic } \\
\text { and obese animals. }\end{array}$
\end{tabular}

\section{Introduction (optional)}

The World Health Organization has been warning about the obesity epidemic affecting different age and socioeconomic groups. Studies have shown the prevalence of diseases associated with obesity, such as gastroesophageal reflux disease (GERD). GERD is a chronic condition resulting from the reflux of stomach contents, which causes tissue damage and symptoms such as heartburn and acid regurgitation. Due to tissue damage and local inflammation, defense cells are present in this process, as they indicate an inflammatory process. An example is the presence of neutrophils at the site, characterized by the activity of the enzyme myeloperoxidase (MPO). Currently, the pharmacological therapy used is proton pump inhibitors (PPIs), such as lansoprazole (LZ), which acts by binding to H+/ATPase enzymes and inhibiting the release of $\mathrm{H}+$ into the gastric lumen. Most of the time, PPIs are effective, but their longterm treatment can have a variety of side effects. New therapeutic targets, such as products from medicinal plant sources, end up being much sought after, due to their greater availability and better efficacy. Among them, there is citral (CT), a monoterpene that is present in the composition of essential oils from plants, such as lemongrass. This monoterpene has several proven pharmacological properties: anti-inflammatory, anti-diabetic, anti-adipogenic and gastroprotective action in the treatment of ulcers induced by non-steroidal anti-inflammatory drugs (NSAIDs). However, there are no data in the literature that demonstrate the action of CT in combating GERD, in in vivo and in vitro studies. Therefore, this project aimed to evaluate the effect of CT on GERD in eutrophic and obese animals.

\section{Materials and Methods (optional)}

Male mice (C57BL/J6) received standard diet (SD) or high-fat diet (HFD) for 18 weeks to induce obesity (CEUA n $\left.{ }^{\circ} 7707010620\right)$. To perform the acute treatment, the animals were divided into groups: Tween 80 to $1 \%$ - Vehicle; Lz - Lansoprazole; CT25 - Citral 25 mg/kg; CT100 - Citral 100 mg/kg; CT300 Citral $300 \mathrm{mg} / \mathrm{kg}$; Sham - animals subjected to surgical stress and without treatment. The mice were orally treated by gavage (single dose) and, after one hour, underwent the surgical procedure for 
implantation of gastroesophageal reflux, being euthanized after four hours to collect the esophagus. Body weight gain, adiposity index, food intake, glycemic index, lesion area, measurement of esophageal $\mathrm{pH}$ and evaluations of the inflammatory process via determination of MPO activity were analyzed. Results were expressed as mean \pm S.E.M. and statistical significance was determined by Student's t-test and oneway or two-way ANOVA followed by Tukey's test $(\mathrm{p}<0.05)$.

\section{Results and Discussion (optional)}

During the obesity induction period, the animals in the HFD group showed a significant increase in body weight (16\%) and in the adiposity index (68\%), when compared to the SD group. The results demonstrate that previous treatment with CT in both animals that received SD and HFD (at doses of 25 and 300 $\mathrm{mg} / \mathrm{kg}$ ) was effective in preventing gastroesophageal reflux-induced lesions, in relation to the vehicle group. The results also showed that in the SD group, there was a decrease in the esophageal $\mathrm{pH}$ of the animals that received the dose of $100 \mathrm{mg} / \mathrm{kg}$ of CT, when compared to the Sham group (CT $100 \mathrm{vs}$ Sham, $4.7 \pm 015$ vs. $5.6 \pm 0.21$ ). Regarding the HFD group, the animals treated with LZ and with CT, at a dose of $300 \mathrm{mg} / \mathrm{kg}$, showed a significant difference when compared to the vehicle and Sham groups (CT 300 vs. Vehicle, $5.8 \pm 0.12$ vs. $5.1 \pm 0.22$; CT 300 vs. Sham, $5.8 \pm 0.12$ vs. $4.8 \pm 0.16$; LZ vs. Vehicle, $5.8 \pm$ 0.12 vs. $5.1 \pm 0.22$; $\mathrm{LZ}$ vs. Sham, $5.8 \pm$ vs. $4.8 \pm 0.12$ ). The MPO enzyme activity was quantified and there was a significant reduction in the group treated with the dose of $300 \mathrm{mg} / \mathrm{kg}$, when compared to the vehicle group in the SD group (CT 300 vs. Vehicle, $4.1 \pm 0.72$ vs. $12.1 \pm 2.27$ ). In the HFD group, this reduction in MPO activity was evident in the LZ, CT100 and CT300 groups, when compared to their vehicle group (LZ vs. Vehicle, $5.3 \pm 0.67$ vs. $13.1 \pm 0.67$; CT 100 vs. Vehicle, $5.3 \pm 0.82$ vs. $13.1 \pm 0.67$; CT 300 vs. Vehicle, $4.7 \pm 1.53$ vs. $13.1 \pm 0.67)$.

\section{Conclusions (optional)}

Thus, it was observed that CT had a protective effect on GERD in groups treated with a higher dose of CT in eutrophic and obese animals. Based on the literature and the results obtained, CT is a potential therapeutic target for several diseases, such as that of the gastrointestinal tract, including GERD.

\section{References (mandatory)}

- HO. https://www.who.int/ (2021).

- Saúde, M. da. Vigitel Brasil 2018: Vigilância de fatores de risco e proteção para doenças crônicas por inquerito telefônico. G. Estatística e Informação em Saúde (2019).

- Reilly, S. M. \& Saltiel, A. R. Adapting to obesity with adipose tissue inflammation. Nat. Rev. Endocrinol. 13, 633-643 (2017).

- Schlottmann, F., Dreifuss, N. H. \& Patti, M. G. Obesity and esophageal cancer: GERD, Barrett's esophagus, and molecular carcinogenic pathways. Expert Rev. Gastroenterol. Hepatol. 14, 425-433 (2020).

- Nakahara, K. et al. Acid reflux directly causes sleep disturbances in rat with chronic esophagitis. PLoS One 9, (2014).

- Gorodner, V., Viscido, G., Signorini, F., Obeide, L. \& Moser, F. Gastroesophageal reflux disease and morbid obesity: evaluation and treatment. Updates Surg. 70, 331-337 (2018).

- Aratani, Y. Myeloperoxidase: Its role for host defense, inflammation, and neutrophil function. Arch. Biochem. Biophys. 640, 47-52 (2018).

- Shibli, Fahmi, Yoshitaka Kitayama, and Ronnie Fass. "Novel therapies for gastroesophageal reflux disease: beyond proton pump inhibitors." Current gastroenterology reports 22.4 (2020): 1-13.

- Clarrett, Danisa M., and Christine Hachem. "Gastroesophageal reflux disease (GERD)." Missouri medicine 115.3 (2018): 214.

- Périco, Larissa Lucena, et al. "Systematic analysis of monoterpenes: Advances and challenges in the treatment of peptic ulcer diseases." Biomolecules 10.2 (2020): 265. 
MOL2NET, 2019, 5, ISSN: 2624-5078

http://sciforum.net/conference/mol2net-05

- Bailly, Christian. "Targets and pathways involved in the antitumor activity of citral and its stereoisomers." European journal of pharmacology 871 (2020): 172945. 